\title{
The Comparative Analysis of Optimal Designed Web Expanded Beams via Improved Harmony Search Method
}

\author{
[ Ferhat Erdal, Osman Tunca, Serkan Taş ]
}

\begin{abstract}
This study aims at comparing the optimum design of two common types open web expanded beams: with hexagonal openings, also called castellated beams and beams with circular openings referred to as cellular beams. The minimum weights of both beams are taken as the objective functions while the design constraints are respectively implemented from The Steel Construction Institute Publication Numbers 5 and 100. The design methods adopted in these publications are consistent with BS5950 parts. The formulation of the design problem considering the limitations of the above mentioned turns out to be a discrete programming problem. Improved harmony search (IHS) algorithm is suggested to compare the optimum design of mentioned web-expanded beams to analysis the performance of both beams. The design algorithms based on the technique select the optimum Universal Beam sections, dimensional properties of hexagonal and circular holes and total number of openings along the beam as design variables.
\end{abstract}

Keywords - structural optimization, web expanded beams, castellated beams, cellular beams, harmony search algorithm.

\section{Introduction}

Web-expanded beams provide economical solution and pleasing appearance for large span structures. Decrease in story height reduces interior volume and exterior surface of building and these results in cost saving. Furthermore, in comparison with solid web and web opening beams, webexpanded beams can easily increase the shear capacities, vertical bending stiffness and capacities of structure. Open web-expanded beams can be fabricated where architectural or structural solutions dictate standard steel sections inappropriate. This is achieved by cutting the web of a hot rolled beam in a certain pattern and then welding two halves together to form a deeper section. As a result of these cutting and welding back processes, beams will have a deeper section and greater resistance to deflection than a comparable original solid section. Castellated beams are initially split along their length by a profiled single flame cut. Two halves of the beam are then separated and welded back together. The fabrication process of cellular beams is slightly different from castellated beams. These beams are manufactured by twice cutting an original rolled beam web in a half circular pattern along its centerline, then separating tee parts and re-welding these two halves.

Ferhat Erdal/Assist. Prof. Dr.

Department of Civil Engineering / Akdeniz University

Antalya/Turkey

Osman Tunca/Research Asist.

Department of Civil Engineering / Karamanoglu MehmetbeyUniversity

Karaman/Turkey

Serkan Taş/Msc Student

Department of Civil Engineering / Akdeniz University

Antalya/Turkey
This study is concerned with the application of IHS algorithm for the mentioned web-expanded beams. HS method originated by Geem is based on the musical performance process that takes place when a musician searches for a better state of harmony [1]. Jazz improvisation seeks musically pleasing harmony similar to the optimum design process which seeks to find the optimum solution. The pitch of each instrument determines the aesthetic quality, just as the objective function value is determined by the set of values assigned to each variable. The minimum weight design of both beams requires the selection of beams from UB section list such that both beams satisfy the strength and serviceability constraints.

\section{Design of Cellular Beams}

The design of a cellular beam has need for the selection of a rolled beam from which the beam is to be produced, the selection of circular hole diameter and the selection of spacing between the centers of these circular holes or total number of holes in the beam as shown in Fig. 1.
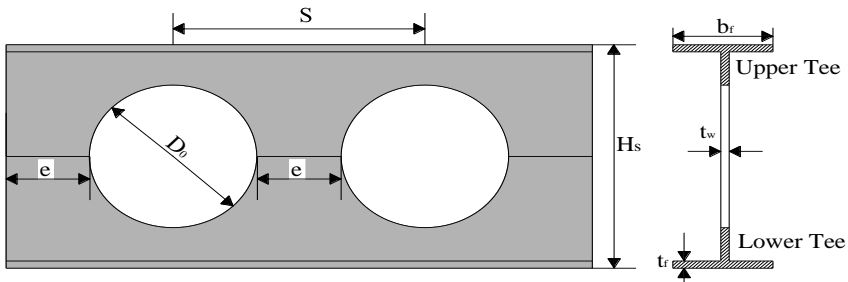

Figure 1. Design variables for a cellular beam

In consequence the number of the rolled beam sections in the standard sections tables, the circular opening diameter and the total number of holes are taken as design variables in the design problem considered. For that purpose a design pool is prepared which consists of list of standard rolled beam sections, a list of various diameter sizes for the total number of holes in a cellular beam. The optimum design problem formulated considering the design constraints explained in "Design of Composite and Non-composite Cellular Beams" [2] which are consistent with BS5950 [3]; Part 1 and 3 yields the following mathematical model. Find a integer design vector $\{I\}=\left\{I_{1}, I_{2}, I_{3}\right\}^{T}$ where $I_{1}$ is the sequence number for rolled beam section in the standard steel sections list, $I_{2}$ is the sequence number for the hole diameter in the discrete set which contains various diameter values and $I_{3}$ is the total number of holes for the cellular beam. Once $I_{l}$ is selected, then the rolled steel beam designation becomes known and all cross sectional properties of the beam becomes available for design. The corresponding values to $I_{2}$ and $I_{3}$ in the design sets makes the hole diameter and the total number of holes available for the cellular beam. Hence the design problem turns out to be minimize the weight of the cellular beam: 


$$
W_{c e l}=\rho_{s} A L-\rho_{s}\left(\pi\left(D_{0} / 2\right)^{2} N_{H}\right)
$$

Subject to;

$$
\begin{array}{lll}
g_{1}=1.08 \times D_{0}-S \leq 0 & \text { (2) } & g_{2}=S-1.6 \times D_{0} \leq 0 \\
g_{3}=1.25 \times D_{0}-H_{S} \leq 0 & \text { (4) } & g_{4}=H_{S}-1.75 \times D_{0} \leq 0 \\
g_{5}=M_{U}-M_{P} \leq 0 & \text { (6) } & g_{6}=V_{\max \text { sup }}-P_{v} \leq 0 \\
g_{7}=V_{O \max }-P_{v y} \leq 0 & \text { (8) } & g_{8}=V_{H \max }-P_{v h} \leq 0 \\
g_{9}=M_{A-A \max }-M_{w \max } \leq 0 & \text { (10) } & g_{10}=V_{T e e}-0.5 \times P_{v y} \leq 0 \\
g_{11}=P_{0} / P_{u}-M / M_{p}-1 \leq 0 & \text { (12) } g_{12}=y_{\max }-L / 360 \leq 0
\end{array}
$$

Where $W_{c e l}$ is the weight of the cellular beam, $D_{0}$ is hole diameter, $\rho_{s}$ is density of steel, $A$ is total area of profile, $N_{H}$ is number of holes, $H_{s}$ is overall depth of cellular beam, $L$ is span of cellular beam and $S$ is distance between centers of holes. $M_{U}$ is maximum moment under loading, $M_{P}$ is plastic moment capacity $W_{\text {maxsup }}$ is max. shear at support $W_{\text {Omax }}$ is max. shear at opening, $W_{H \max }$ is max. horizontal shear, $M_{A \text { - }}$ ${ }_{\text {Amax }}$ is max. moment at A-A section, $M_{\text {wmax }}$ is the allowable web post moment, $W_{\text {Tee }}$ is vertical shear on tee, $P_{0}, M$ are forces on the section and $y_{\max }$ is max. deflection. Although the diameter of holes and spacing between their centers are left to designer to select, the geometric limitations given in constraints (2)-(4) are required to be observed. Eq. (6) represents overall beam flexural capacity limitation. Under load combinations the cellular beam should have sufficient flexural capacity to be able to resist the external loading. There are three shear checks in the design of cellular beams. The first one is shear check at the support. Eq. (7) makes sure that shear at the support does not exceed the shear capacity of the section. The first shear check Eq. (8) is the vertical shear capacity check of the beam. The sum of the shear capacities of tees gives the vertical shear capacity. The factored shear force in the beam should not exceed allowable vertical shear. The other Eq. (9) is the horizontal shear check. The horizontal shear is developed in the web post due the change in axial forces [4]. The flexural capacity under bending is also critical in beams. The transfer of shear forces across a single opening causes secondary bending stresses. Eqs. (10-12) are required for the flexural and buckling strength of web post. Eq. (13) is the serviceability requirement that the cellular beam has to satisfy.

\section{Design of Castellated Beams}

Since the 1950 s the high strength-to-weight ratio of castellated beams has been a desirable feature for structural engineers in their efforts to design even lighter and more cost-efficient steel structures. The design process of castellated beams is different from cellular beams as they do not have the same geometrical properties.

Figure 2. Design variables for a castellated beam

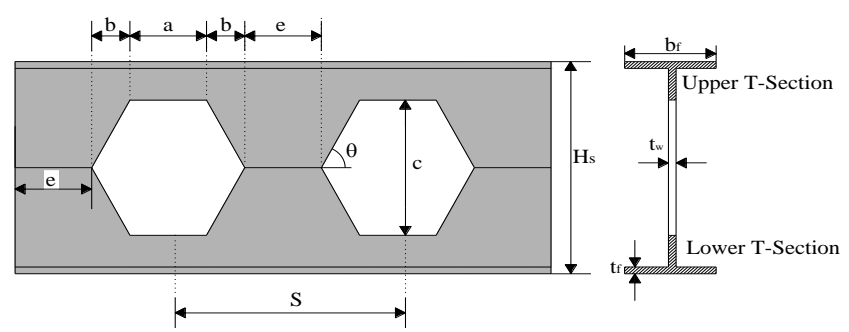

The strength of a castellated beam shall be determined based on the interaction of flexure and shear at the hexagonal opening. Design constraints include the displacement limitations, overall beam flexural capacity, beam shear capacity, overall beam buckling strength, web-post flexure and buckling, Vierendeel bending of the upper and lower tees, local buckling of the compression flange and practical restrictions between the hexagonal hole dimensions and the spacing between openings. The design procedure given here is taken from Steel Construction Institute Publication No. 005, entitled "Design of Castellated Beams" [5]. The design methods are consistent with BS5950 parts 1 and 3, and BS449. The standard profile geometry and notations used for castellated beams are shown in Fig. 2. The dimensions of the beam are described in the following equations:

$$
\begin{aligned}
& a=0.5 \times(S-2 \times c \times \cot \theta) \\
& b=c \times \cot \theta \\
& S=2 \times(a+b) \\
& H_{S}=h_{f}+c
\end{aligned}
$$

where $\mathrm{S}$ is the spacing between the centres of the holes, $h_{f}$ is the depth of the original section, $H_{s}$ is the final depth of the castellated beam, a, b and $\mathrm{c}$ are the dimensions of the hexagonal holes. The design properties and dimensions of the castellated beam are considered as constraints. The optimum design of a castellated beam requires the selection of the design variables, called the sequence number of universal beam sections in the standard steel sections tables, the hexagonal hole depth, the angle between the edges and the total number of hexagonal holes. Changing the angle of the hexagonal hole in the optimum design of castellated beams has a considerable effect on the minimum weight and it is more appropriate to consider parameters such as an additional design variable if a better design is looked for. Besides the sequence number of universal beam sections, the depth of the hexagonal holes and the total number of hexagonal holes, the angle between the edges which is varied from $50^{\circ}$ to $70^{\circ}$ is added as the fourth design variable to demonstrate this effect and the design of the castellated beam. For this purpose, a design pool is prepared which consists of a list of standard UB beam sections ranging from $254 \times 102 \times 28$ to $914 \times 419 \times 388$, a list of various hexagonal depth sizes, a list of angle values and a list of integer numbers ranging from 2 to 40 for the total number of holes in the cellular beam. Let us find an integer design vector $\{I\}$ $=\left\{I_{1}, I_{2}, I_{3}, I_{4}\right\}^{T}$ where $I_{1}$ is the sequence number for the UB beam section in the standard steel sections list, $I_{2}$ is the sequence number for the hexagonal depth size in the discrete set which contains various depth values, $I_{3}$ is the angle between the edges and $I_{4}$ is the total number of holes for the castellated beam. Hence the design problem turns out to be to minimize the weight of the castellated beam:

$$
W_{\text {cas }}=\rho_{s} A L-\rho_{s}\left(N_{H} \times c(a+b)\right)
$$

where $W_{\text {cas }}$ denotes the weight of the castellated beam. $A$ represents the total cross-sectional area of the universal beam section selected for the castellated beam, $L$ is the span of the castellated beam, $C$ is the depth of the hexagonal holes and $N_{H}$ is the total number of holes in the castellated beam. The castellated beam is also subject to a number of behavioral restrictions as given in Eqns. (6)-(13). 


\section{Optimization Techniques}

A combinatorial optimization problem requires exhaustive search and effort to determine an optimum solution which is computationally expensive and in some cases may even not be practically possible. Meta-heuristic search techniques are established to make this search within computationally acceptable time period. Amongst these techniques are firefly algorithm [6], particle swarm optimizer [7], genetic algorithms [8] and others. All of these techniques implement particular meta-heuristic search algorithms that are developed based on simulation of a natural phenomenon into numerical optimization procedure. An improved HS algorithm is proposed in this paper as an efficient algorithm for solving web-expanded beams optimization problems. The robustness of the algorithm lies in its capability to implement the aforementioned HS parameters dynamically and update them during the search for the most efficient optimization process.

\section{v. Improved HS Algorithm}

In the classical HS method the parameters harmony memory considering rate $(\eta)$ and pitch adjusting rate $(\rho)$ are selected prior to the application of the method and they are kept constant until the end of the iterations. The numerical applications have shown that the selection of values for $\eta$ and $\rho$ is problem dependent and the initial values selected affect the performance of the algorithm. Consequently, in order to determine the appropriate values of the harmony search parameters it is necessary to solve the optimization problem several times with different values and select the solution with minimum weight. It is apparent that such application devaluates the efficiency of the algorithm. In order to overcome this discrepancy, numbers of improvements are suggested in the literature. First, Mahdavi has proposed an improved harmony search algorithm that uses variable $\rho$ and $b w$ in improvisation step where $b w$ is an arbitrary distance bandwidth [9]. And then, Hasançebi suggested adaptive HS where $\eta$ and $\rho$ are adjusted by the algorithm itself automatically using probabilistic sampling of control parameters [10]. Hence the algorithm tunes these parameters to advantageous values online during search. In the present study, different strategies are proposed for $\eta$ and $\rho$ to compare the minimum weight design of both beams. $\rho$ is updated using the concept suggested by Coelho and Bernert [11]. Before initiating the design process, a set of steel beam sections selected from an available UB profile list are collected in a design pool. Each steel section is assigned a sequence number that varies between 1 to total number of sections $\left(N_{s e c}\right)$ in the list. The basic components of IHS method can now be outlined as follows.

\section{A. Initialization of a parameter set}

First a HS related parameter set is specified. $\eta$ and $\rho$ are dynamic parameters that vary from one solution vector to another, and are set to initial values of $\eta^{(0)}$ and $\rho^{(0)}$ for all the solution vectors in the initial memory matrix. It is worthwhile to mention that in the standard HS algorithm parameters are treated as static quantities, and hence they are assigned to suitable values chosen within their recommended ranges of $\eta \in[0.70,0.95]$ and $\rho \in[0.20,0.50]$.

\section{B. Initialization of memory matrix}

Harmony memory matrix $\mathbf{H}$ is generated randomly initialized next. This matrix represents a design population for the solution of a problem under consideration, and incorporates a specified number of solutions referred to as harmony size $(\mu)$. Each solution vector $\left(\mathrm{I}^{\mathrm{i}}\right)$ consists of $N_{d}$ design variables integer number between 1 to $N_{s}$ (number of values) selected randomly each of which corresponds sequence number of design variables in the design pool, and is represented in a separate row of the matrix; consequently the size of $\mathbf{H}$ is ( $\left.\mu \mathrm{x} N_{d}\right) I_{i}^{j}$ is the sequence number of the $\mathrm{i}^{\text {th }}$ design variable in the $\mathrm{j}^{\text {th }}$ randomly selected feasible solution.

$$
\mathbf{H}=\left[\begin{array}{cccc}
I_{1}^{1} & I_{2}^{1} & \ldots & I_{N_{d}}^{1} \\
I_{1}^{2} & I_{2}^{2} & \ldots & I_{N_{d}}^{2} \\
\ldots & \ldots & \ldots & \ldots \\
I_{1}^{\mu} & I_{2}^{\mu} & \ldots & I_{N_{d}}^{\mu}
\end{array}\right] \phi\left(\mathbf{I}^{1}\right)
$$

\section{Evaluation of memory matrix}

$\mu$ solutions shown in Eq. (19) are then analyzed, and their objective function values are calculated. The solutions evaluated are sorted in the memory matrix.

\section{Improvising a new harmony}

Upon sampling of a new set of values for parameters, the new vector $I^{\prime}=\left[I_{1}, I_{2}, \ldots, I_{n v}\right]$ is generated. In the HM consideration, each variable is selected at random from either memory matrix. The probability that a variable is selected from the HM is controlled by a harmony memory considering rate $(\eta)$. To execute this probability, a random number $r_{i}$ is generated between 0 and 1 for each variable $I_{i}$. If $r_{i}$ is smaller than or equal to $\eta$, the variable is chosen from $\mathrm{HM}$ in which case it is assigned any value from the $i$-th column of the $\mathbf{H}$, representing the value set of variable in $\mu$ solutions of the matrix (Eq. 20). If $r_{i}>\eta$, a random value is assigned to the variable from the discrete set.

$$
I_{i}^{\prime}=\left\{\begin{array}{cc}
I_{i}^{\prime} \in\left\{I_{i}^{1}, I_{i}^{2}, \ldots, I_{i}^{\mu}\right\} & \text { if } r_{i} \leq \eta \\
I_{i}^{\prime} \in\left\{1, . ., N_{S}\right\} & \text { if } r_{i}>\mu
\end{array}\right.
$$

If a variable attains its value from HM, it is checked whether this value should be pitch-adjusted or not. Pith adjustment means sampling the variable's one of the neighboring values, obtained by subtracting one from its current value. Similar to $\eta$ parameter, it is operated with a probability known as pitch adjustment rate ( $\rho)$, Eqn. (21).

$I_{i}^{\prime \prime}=\left\{\begin{array}{cl}I_{i}^{\prime} \pm 1 & \text { if } r_{i} \leq \rho \\ I_{i}^{\prime} & \text { if } r_{i}>\rho\end{array}\right.$

\section{E. Updating parameters}

$$
\rho_{(I)}=\rho_{(M I N)}+\left(\rho_{(M A X)}-\rho_{(M I N)}\right) \times D e g_{(I)}
$$

where, $\rho_{(I)}$ is the pitch adjusting rate for generation $I$, $\rho_{(M I N)}$ is the minimum adjusting rate, $\rho_{(M A X)}$ is the maximum 
adjusting rate, and $i$ is the generation number. $\operatorname{Deg}_{(I)}$ is updated according to the following expression:

$$
\operatorname{Deg} g_{(I)}=\frac{\left(H \operatorname{COST} T_{M A X(I)}-H \operatorname{COST} T_{M E A N}\right)}{\left(H \operatorname{COST} T_{M A X(I)}-H C O S T_{M I N(I)}\right)}
$$

where, $H C O S T_{M A X(i)}$ and $H C O S T_{M I N(i)}$ are the maximum and minimum function objective values in generation $I$, respectively; $H C O S T_{M E A N}$ is the mean of objective function value of the memory matrix. The improvisation of $\eta$ is carried out using following expression;

$$
\eta_{(I)}=\eta_{(M A X)}-\left(\eta_{(M A X)}-\eta_{(M I N)}\right) \times D e g_{(I)}
$$

where, $\eta_{(I)}$ is the harmony considering rate for generation $I, \eta_{(M A X)}$ is the maximum considering rate, $\eta_{(M I N)}$ is the minimum considering rate, and $I$ is the generation number.

\section{F. Adaptive constraint handling}

Once the new vector is obtained using the abovementioned rules, it is then checked whether it violates problem constraints. If the new vector is slightly infeasible, it is included in the $\mathbf{H}$. In this way the violated vector which may be infeasible slightly in one or more constraints is used as a base in the pitch adjustment operation to provide a vector that may be feasible. This is carried out by using larger error values initially for the acceptability of the new vectors and then this value is adjusted during the design cycles according to the expression given below;

$$
\operatorname{Er}(i)=E r_{M A X}-\left(E r_{M A X}-E r_{M I N}\right) / \sqrt{N_{S}} \times \sqrt{i}
$$

where, $\operatorname{Er}(i)$ is the error value in iteration $i, E r_{M A X}$ and $E r_{M I N}$ are the maximum and the minimum errors defined in the algorithm respectively, $N_{s}$ is the maximum iteration number until which tolerance minimization procedure continues. Eq. 24 provides larger error values in the beginning of the design cycles.

\section{G. Update of Harmony Matrix}

After generating the new vector, its objective function value is calculated. If this value is better than that of the worst vector in the harmony memory, it is then included in the matrix while the worst one is discarded out of the matrix.

\section{H. Termination}

Steps 3 and 4 are repeated until a pre-assigned maximum number of cycles are reached.

\section{vI. Design Example}

A typical 12-m span intermediate steel beam shown in Fig. 3 is considered as a design example to compare the minimum weight of steel castellated and cellular beams.

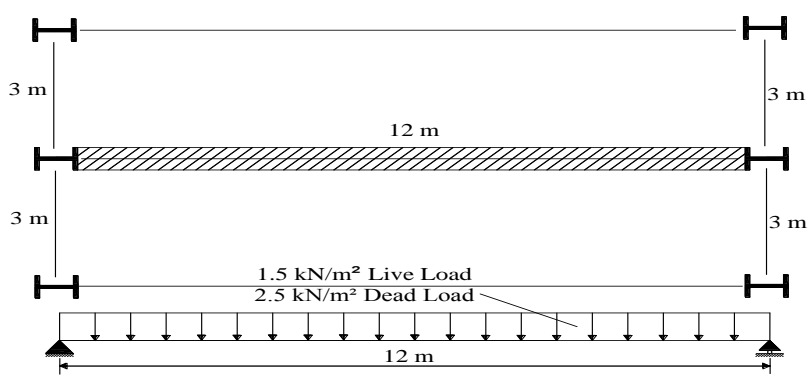

Figure 3. Loading of 12-m intermediate steel beam
The beam is subjected to the uniform dead load of 2.5 $\mathrm{kN} / \mathrm{m}^{2}$ including concrete slab, steel deck, reinforcement and steel beam and a live load of $1.5 \mathrm{kN} / \mathrm{m}^{2}$ in addition its own dead weight. The upper flange of the beam is laterally supported by the floor system that it supports. Beam spacing is $3 \mathrm{~m}$. The maximum displacement of the beam under the live-load is restricted to be less than $L / 360$, where $L$ is the length of the beam. This design example is separately solved as castellated and cellular beams using improved harmony search algorithm. The size of the maximum number of generations is kept the same for both beams. The values of $\eta_{(M A X)}$ and $\rho_{(M A X)}$ parameters in the IHS algorithm are taken as 0.99 and the 0.01 is assigned to $\eta_{(M I N)}$ and $\rho_{(M I N)}$. These values are dynamically updated by the proposed algorithm during the optimization process as a feature of the proposed technique.

TABLE I. Optimum solutions of 12-m span intermediate beam

\begin{tabular}{|c|c|c|r|r|c|c|}
\hline \multicolumn{7}{|c|}{ Improved Harmony Search Algorithm } \\
\hline & $\begin{array}{c}\text { Section } \\
\text { Design } \\
(\text { UB })\end{array}$ & $\begin{array}{c}\text { Diameter } \\
\text { /Depth } \\
\text { of Hole }\end{array}$ & $\begin{array}{c}\text { Number } \\
\text { of } \\
\text { Holes }\end{array}$ & $\begin{array}{c}\text { Value } \\
\text { of } \\
\text { Angle }\end{array}$ & $\begin{array}{c}\text { Maximum } \\
\text { Strength } \\
\text { Ratio }\end{array}$ & $\begin{array}{c}\text { Minimum } \\
\text { Weight } \\
(\mathrm{kg})\end{array}$ \\
\hline $\begin{array}{c}\text { Cellular } \\
\text { Beam }\end{array}$ & $356 \times 127 \times 39$ & 366 & 25 & - & 0.99 & $\mathbf{4 3 6 . 7}$ \\
\hline $\begin{array}{c}\text { Castellated } \\
\text { Beam-VA }\end{array}$ & $356 \times 127 \times 39$ & 359 & 24 & 57 & 0.98 & $\mathbf{4 5 7 . 2}$ \\
\hline $\begin{array}{c}\text { Castellated } \\
\text { Beam-FA }\end{array}$ & $356 \times 171 \times 45$ & 341 & 26 & 60 & 0.94 & $\mathbf{5 2 8 . 4}$ \\
\hline
\end{tabular}

This design example is separately solved as both beams using IHS algorithm. The size of the maximum number of generations is kept the same for both beams. The values of $\eta_{(M A X)}$ and $\rho_{(M A X)}$ parameters in the IHS algorithm are taken as 0.99 and the 0.01 is assigned to $\eta_{(M I N)}$ and $\rho_{(M I N)}$. These values are dynamically updated by the proposed algorithm during the optimization process. It is apparent from the Table I that IHS algorithm produces a least weight for a cellular beam which is equal to $436.7 \mathrm{~kg}$. The optimum cellular beam shown in Fig. 5 should be produced such that it should have 25 circular holes each having $366 \mathrm{~mm}$ diameter. The controlling interaction ratios of steel cellular beam are 0.99 for bending moment, 0.78 for web-post buckling and 0.62 for horizontal shear. Changing the angle of hexagonal hole in the optimum design of castellated beams has a considerable effect on the minimum weight. Besides the sequence number of a universal beam sections, the depth of hexagonal hole and the total number of hexagonal holes, angle between the edges is added as fourth design variable to demonstrate this effect and design of castellated beam. The optimum castellated beam shown in Fig. 6 is obtained by considering four design variables. It is apparent from Table that the optimum design has the minimum weight of $457.2 \mathrm{~kg}$ which selects $356 \times 127 \times 39 \mathrm{UB}$ section for the root beam. When the optimum design problem is carried out considering only fixed angle $\left(\theta=60^{\circ}\right)$, the minimum weight of the castellated beam turns out to be 528.4 $\mathrm{kg} ; 15.57 \%$ heavier than the castellated beam with varying angle. The controlling interaction ratios of castellated beam are 0.94 for bending moment, 0.80 for web-post buckling and 0.53 for horizontal shear. These results clearly reveal the fact that, in both beams, bending moment constraints are dominant in this particular problem. The design history curve for cellular beam, castellated beam with fixed angle 
and castellated beam with varying angle is shown in Fig. 4. It is apparent from Fig. 4 that IHS performs the nearly same convergence rate and produces same steel sections for cellular beam and castellated beam with varying angle.

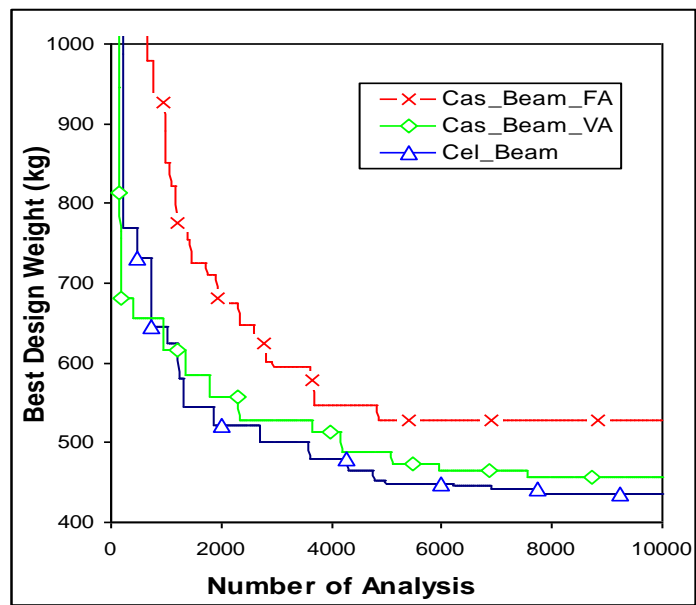

Figure 4. Design history graph of intermediate beam

The optimum shapes of the cellular beam and castellated beam with varying angle obtained from IHS method is demonstrated in Fig. 5 and Fig. 6, respectively.

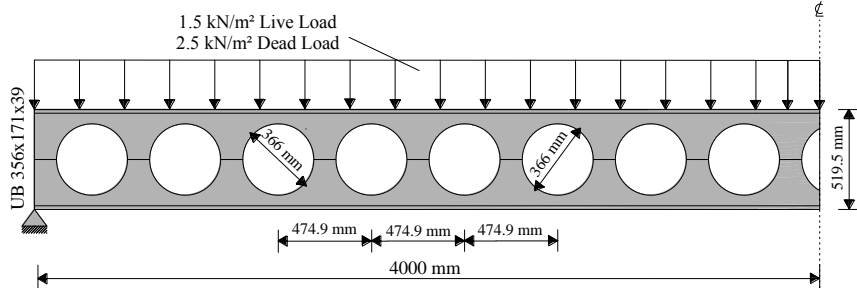

Figure 5. One-third of optimum steel cellular beam

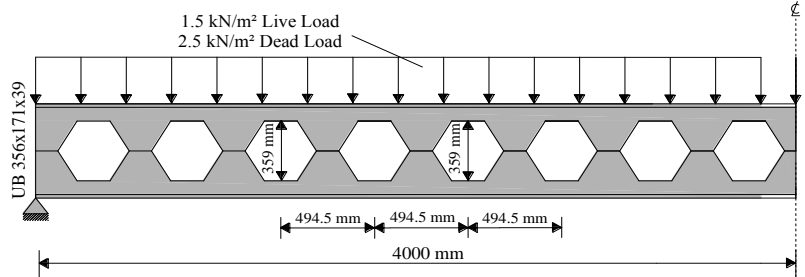

Figure 6. One-third of optimum steel castellated beam

\section{vII. Conclusions}

The present research is the study to cover a comparison of the optimally designed castellated and cellular beams using one of the search techniques. An improved version of HS algorithm is also developed in this paper as a robust method for effectively dealing with a rectangular welded beam problem. Unlike the classical algorithm where the update parameters of the technique are assigned to constant values throughout the search, the proposed algorithm benefits from updating these control parameters to advantageous values online during the iteration process. The efficiency of the IHS algorithm is numerically examined using an example on size optimum design of castellated and cellular beams. In design example, castellated beam with varying angle produces $15.57 \%$ lighter weight than the castellated beam with fixed angle. More exactly, changing the angle of hexagonal hole in the optimum design of steel castellated beams has a considerable effect on the optimum design and it is more appropriate to consider this parameter as an additional design variable if a better design is looked for. It is apparent from the table that IHS finds same sections for both beams with varying angle but the proposed method finds the less weight for steel cellular beam due to the two cutting process and waste parts between the half circles. The results obtained by the application of IHS demonstrate that cellular beams produce a more cost-effective solution than castellated beams as a result of their flexible geometry and they have several different diameters of circular hole are possible without change in the fabrication process.

\section{Acknowledgment}

This paper is partially based on research supported by the Scientific Research Projects Coordination Units of Akdeniz and Akdeniz University Research Funding (BAP), which is gratefully acknowledged.

\section{References}

[1] Geem Z.W. and Kim J.H. (2001), A new heuristic optimization algorithm: harmony search. Simulation, 76, 60-68.

[2] Ward J.K. (1990), Design of composite and non-composite cellular beams, The Steel Construction Institute Publication.

[3] British Standards, BS 5950 (2000), Structural Use of Steelworks in Building. Part 1 and 3 Code of Practice for Design in Simple and Continuous construction, hot rolled sections, BSI, London, U.K.

[4] Erdal F., Doğan E. and Saka M.P. (2011), Optimum design of cellular beams using harmony search and particle swarm optimizers, Journal of Constr. Steel Research, 67(2), 237-247.

[5] Knowles, P.R. (1980), Design of castellated beams for use with BS 5950 and BS 449, Weldable Structures steel produced to BS:Part 1. Gandomi A.H., Yang X.S. and Alavi A.H. (2011), Mixed variable structural optimization using firefly algorithm, Computers and Structures, 89(23-24), 2325-36.

[7] Kennedy, J., Eberhart R. and Shi, Y. (2001) Swarm Intelligence. Morgan Kaufmann Publishers.

[8] Goldberg, D.E. (1989) Genetic algorithms in search, Optimization and Machine Learning. Addison Wesley.

[9] Mahdavi M., Fesanghary M. and Damangir E. (2007), An improved harmony search algorithm for solving optimization problems, Applied Math. and Computation, 188(2), 1567-1579.

[10] Hasançebi O., Erdal F. and Saka M.P. (2010), An adaptive harmony search method for structural optimization. Journal of Structural Engineering (ASCE), 136(4), 419-431.

[11] Coelho L.S. and Bernert D.L.A. (2009), An improved harmony search algorithm for synchronization of discrete-time chaotic systems. Chaos, Solitons and Fractals, 41(5), 2526-2532.

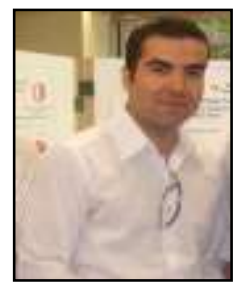

Ferhat Erdal-He graduated from Akdeniz University, in 2003. He undertook his both $\mathrm{MSc}$ and $\mathrm{PhD}$ degrees from Engineering Sciences Department of METU. He professionally deals with the applications of stochastic on structural systems. Lately, he has carried out an experimental research on webexpanded beams. He is in charge of structural mechanics laboratory of in Akdeniz University.

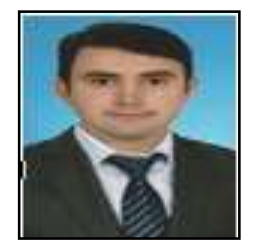

Osman Tunca-He graduated from Aksaray University, in 2010. He undertook his MSc degrees from Civil Engineering Department of Gaziantep University, in 2013. He is getting $\mathrm{PhD}$ education from, Civil Engineering Department of Akdeniz University.

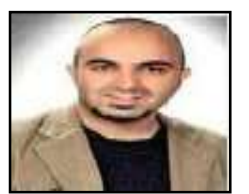

Serkan Taş-He graduated from Akdeniz University, in 2014, in Antalya, Turkey. He is getting MSc education from, Civil Engineering Department of Akdeniz Universitv, in Antalva. 